\title{
Risk factors for mortality in Type II (non-insulin-dependent) diabetes: evidence of a role for neuropathy and a protective effect of HLA-DR4
}

\author{
C.M. Forsblom ${ }^{1}$, T. Sane ${ }^{2}$, P.-H. Groop ${ }^{3}$, K.J. Tötterman ${ }^{1}$, M. Kallio ${ }^{4}$, C. Saloranta ${ }^{1}$, L. Laasonen ${ }^{5}$, P. Summanen ${ }^{6}$, \\ M. Lepäntalo ${ }^{4}$, L. Laatikainen ${ }^{6}$, E. Matikainen ${ }^{7}$, A.-M. Teppo ${ }^{3}$, S. Koskimies ${ }^{8}$, L. Groop ${ }^{9}$ \\ ${ }^{1}$ Department of Medicine, Division of Internal Medicine, Helsinki University Hospital, Helsinki, Finland \\ ${ }^{2}$ Division of Endocrinology, Helsinki University Hospital, Helsinki, Finland \\ ${ }^{3}$ Division of Nephrology, Helsinki University Hospital, Helsinki, Finland \\ ${ }^{4}$ Fourth Department of Surgery, Surgical Hospital, Helsinki, Finland \\ ${ }^{5}$ Department of Radiology, Helsinki University Hospital, Helsinki, Finland \\ ${ }^{6}$ Department of Ophthalmology, Helsinki University Hospital, Helsinki, Finland \\ ${ }^{7}$ Finnish Institute of Occupational Health, Helsinki, Finland \\ ${ }^{8}$ Finnish Red Cross Blood Transfusion Service, Helsinki, Finland \\ ${ }^{9}$ Department of Endocrinology, University of Lund, Malmö, Sweden
}

\begin{abstract}
Summary To test the hypothesis that interaction between genetic, immunological, clinical and metabolic risk factors influences the outcome of Type II (noninsulin-dependent) diabetes mellitus, we examined which of the above factors present at baseline were associated with mortality in 134 Type II diabetic patients followed for 9 years. Thirty-eight patients $(29 \%)$ died during the follow-up period; the majority of whom $(68 \%)$ died from cardiovascular disease. At baseline, the deceased patients had higher $\mathrm{HbA}_{1 \mathrm{c}}$ values $(p=0.002)$, higher LDL-triglycerides $(p=0.007)$, lower HDL-cholesterol $(p=0.007)$, higher non-esterified fatty acid (NEFA) concentrations $(p=0.014)$, and higher albumin excretion rate $(p<0.0001)$ than the patients who survived. In addition, the frequency of HLA-DR4 (21 vs $39 \%, p=0.048)$ and of parietal cell antibodies ( 5 vs $14 \%, p=0.016$ ) were decreased in the deceased as compared to the living patients. Patients who died during follow-up also had more retinopathy (42 vs $16 \%, p=0.002$ ), neuropathy (57 vs $23 \%, p<0.001$ ), microalbuminuria (45 vs $6 \%, p<$ 0.0001 ), coronary heart disease (50 vs $13 \%, p<$
\end{abstract}

$0.0001)$, and peripheral vascular disease (27 vs $9 \%$, $p=0.005)$ at baseline than patients who survived. In a multiple logistic regression analysis macroangiopathy $(p=0.004)$, neuropathy $(p=0.007), \mathrm{HbA}_{1 \mathrm{c}}(p=$ $0.018)$ and albumin excretion rate $(p=0.016)$ were independent risk factors for death. In patients free of cardiovascular disease at baseline, conventional risk factors such as LDL-cholesterol $(p=0.005)$ and age $(p=0.003)$ were associated with subsequent development of cardiovascular disease. In conclusion, in addition to coexisting macroangiopathy, increased albumin excretion rate, poor glycaemic control and neuropathy are risk factors for cardiovascular mortality in patients with Type II diabetes. The presence of HLA-DR4 and signs of autoimmunity may be associated with decreased risk of cardiovascular disease. [Diabetologia (1998) 41: 1253-1262]

Keywords Type II (non-insulin-dependent) diabetes mellitus, HLA-DR4, microalbuminuria, mortality, cardiovascular risk factors, immunological markers, neuropathy, NEFA.
Received: 29 December 1997 and in revised form: 27 April 1998

Corresponding author: Dr. C. M. Forsblom, Helsinki University Hospital, Department of Medicine, Division of Internal Medicine, PL 346, FIN-00029 HYKS, Finland

Abbreviations: AER, Albumin excretion rate; BMI, body mass index; CHD, coronary heart disease; GAD, glutamic acid decarboxylase; NEFA, non-esterified fatty acids; PVD, peripheral vascular disease; $\mathrm{HbA}_{1}$, glycated haemoglobin; PVR, pulse volume recording, WHO, World Health Organisation; LADA, latent autoimmune form of diabetes; MODY, maturity onset diabetes of the young.
The prognosis of patients with Type II (non-insulindependent) diabetes mellitus is primarily determined by the presence of macro- and microangiopathy. There is, however, a large variation in the propensity for the patient to develop these devastating complications. While poor glycaemic control and duration of diabetes are strong predictors of microangiopathy [1], their role as predictors of macroangiopathy is less clear [2-6]. In Type II diabetes, clustering of the metabolic syndrome (hyperglycaemia, obesity, hyper- 
tension, hyperinsulinaemia, dyslipidaemia, and microalbuminuria) is associated with a particularly poor prognosis due to excess cardiovascular mortality [7]. However, only about $60 \%$ of Type II diabetic patients show features of the metabolic syndrome [8]. Among the remaining patients, about $10 \%$ have glutamic acid decarboxylase (GAD) antibodies and represent a latent autoimmune form of diabetes (LADA) $[9,10]$. Genetic heterogeneity may further obscure the picture. The monogenic maturity onset diabetes of the young (MODY) forms are characterised by insulin deficiency, but normal insulin sensitivity [11] and less frequency of cardiovascular disease [12]. Increased prevalence of HLA-DR4 has been reported in Type II diabetic patients, but this increase was confined to patients with relative insulin deficiency [13]. In addition, HLA-DR4 has been shown to be associated with microangiopathy, particularly retinopathy in Type I (insulin-dependent) diabetic patients [14]. It is therefore likely that Type II diabetes includes a broad spectrum of disorders, in which disease heterogeneity influences susceptibility to diabetic complications.

To test the hypothesis that the interaction between clinical, genetic, immunological and metabolic risk factors influences the outcome of Type II diabetes, we examined which of the above factors present at baseline predicted mortality during a 9-year followup period. The design also allowed us to study the interaction between micro- and macroangiopathy as determinants of mortality in patients with Type II diabetes.

\section{Subjects and methods}

\section{Patients and study design}

We randomly selected 134 Type II diabetic patients, aged between 35 and 70 years, from the register of the Helsinki Diabetes Association. Type II diabetes was defined according to World Health Organisation (WHO) criteria [15]. Patients with malignancies or overt diabetic nephropathy $(n=3)$ were excluded and the remaining 131 (67 male/64 female) patients participated in the study. All patients were first studied during the period $1983-1985$, and all available patients $(n=86)$ a second time during 1993-1995. Thirty-eight patients had died, while seven did not want to participate in the follow-up study. However, in most of these cases (4 patients) information about their current medical status could be obtained from their medical records. Information on causes of death was obtained from death certificates and medical files. The death certificates were reviewed by two of the authors independently of each other. All patients gave their informed consent and the study protocol was approved by the local ethics committee.

At baseline, all patients underwent a clinical examination with careful assessment of microangiopathy (retinopathy, nephropathy, and neuropathy) and macroangiopathy (cardiovascular and peripheral vascular disease). C-peptide and insulin concentrations were measured in serum samples taken before and $6 \mathrm{~min}$ after an intravenous injection of $1 \mathrm{mg}$ of gluca- gon [16]. Insulin resistance was calculated as (fasting insulin $\times$ fasting glucose $) /(22.5)$, using the homeostasis model assessment (HOMA) model [17]. Fasting blood samples were drawn for the measurements of blood glucose, glycated haemoglobin $\left(\mathrm{HbA}_{1}\right)$, serum total and lipoprotein lipids, and creatinine concentrations. In addition, organ-specific antibody (thyroid microsomal, thyroglobulin, islet-cell, and gastric parietal) concentrations were measured, and HLA-typing was performed. In a subset of patients $(n=64)$ GAD antibodies were measured. Three 24-h urine collections were used for the measurement of urinary albumin excretion (AER) and creatinine clearance. At follow-up, all measurements except the assessment of retinopathy and neuropathy were repeated. However, instead of 24-h urine collections, overnight urine was collected for the measurement of AER.

\section{Assessment of microangiopathy and macroangiopathy}

Retinopathy. The evaluation of the ocular fundi and the severity of retinopathy was assessed by direct ophthalmoscopy and fluorescein angiography. The findings were numerically evaluated with a scale from 0 to 5 . Score 0 indicated no signs of retinopathy; 1 = minimal changes such as less than 10 microaneurysms per eye; 2 = slight background retinopathy with 10 or more microaneurysms per eye; $3=$ moderate background retinopathy with plenty of microaneurysms, several small bleeding spots, lipid exudates and microinfarcts; $4=$ maculopathy which indicated the same findings as in 3 but specifically in the macular region; 5 = proliferative retinopathy characterised by the same findings as in 3 but in addition presence of retinal neovascularisation. Retinopathy was considered present if a patient had 10 or more microaneurysms per eye in the fluorescein angiogram (scores $2-5$ ).

Neuropathy. The findings of the clinical neurological examination were numerically evaluated with a scale from 0 to 12 (neuropathy score). The conduction velocities of peripheral nerves were measured with an electroneuromyography device (DISA Elektronik A/S, Skovlunde, Denmark). If two different nerves showed pathological conduction velocities the patient was considered to have neurophysiologically diagnosed neuropathy. To test the autonomic nervous system, heart rate variation at rest, during maximal 6 deep breaths per min, and during the Valsalva manoeuvre was recorded, and differences in heart rate and blood pressure between supine and postural positions were quantitated. The variation of heart rate was expressed as standard deviation (SD) of means and as the difference between maximum and minimum pulse frequency $(\Delta \mathrm{HR})$.

Albuminuria. Microalbuminuria was defined as AER 30$300 \mathrm{mg} / 24 \mathrm{~h}$ or $20-200 \mu \mathrm{g} / \mathrm{min}$ (in overnight urine collections) and macroalbuminuria as AER greater than $300 \mathrm{mg} / 24 \mathrm{~h}$ or greater than $200 \mu \mathrm{g} / \mathrm{min}$ in two out of three urine collections.

Macrovascular disease. Macroangiopathy was defined as the presence of coronary heart disease (CHD) and/or peripheral vascular disease (PVD) or stroke.

Electrocardiograms were recorded from each study subject and coded using the Minnesota Coding system by one investigator. CHD was defined as a medical history of myocardial infarction and/or the presence of probable myocardial infarction in the electrocardiogram (Minnesota codes 1.1-1.2), or if a patient was both treated with long-acting nitroglycerin and had signs of possible myocardial ischaemia in the electrocardiogram (Minnesota codes 1.3, 4.1-4.4, 5.1-5.3, 7.1)[18]. 
Blood pressure was measured in sitting position after a 15min rest using a mercury sphygmomanometer. The mean value of three measurements obtained at 1-min intervals was calculated. Hypertension was defined as systolic blood pressure $160 \mathrm{mmHg}$ or more and/or a diastolic blood pressure $95 \mathrm{mmHg}$ or more or use of antihypertensive drugs.

Signs of heart failure were identified from a chest X-ray and the heart volume was estimated by an experienced radiologist. Heart volume was expressed as $\mathrm{cc} / \mathrm{m}^{2}$.

Peripheral vascular disease. The non-invasive assessment of PVD included pulse volume recording (PVR), systolic blood pressure measurement at the ankle, calculation of ankle/arm systolic blood pressure ratio and measurement of great toe systolic blood pressure. PVR is a pneumoplethysmographic technique measuring volume changes in the extremity caused by a pulse wave [19]. Ankle blood pressure was measured using a $12-\mathrm{cm}$ wide occluding cuff and Doppler device as a distal sensor [20]. Great toe systolic blood pressure was measured with a 24-mm wide occluding cuff and strain gauge as a distal sensor [21]. The diagnosis of PVD required two of the following criteria: (1) PVR amplitude at the ankle level $10 \mathrm{~mm}$ or less, (2) ankle/arm pressure ratio less than 0.85 and/or (3) great toe systolic blood pressure less than $50 \mathrm{mmHg}$.

Assays. Plasma glucose was assayed by a hexokinase method (Boehringer Mannheim, Mannheim, Germany). Glycohaemoglobin $\left(\mathrm{HbA}_{1}\right)$ concentration in blood was measured by microcolumn cation exchange chromatography (Isolab, Akron, Ohio, USA) after overnight incubation of the samples in saline. The reference level for the assay was 5-7\%. Serum insulin concentrations were measured in duplicate using antiserum M 8170, ${ }^{125} \mathrm{I}($ tyr A 19)-labelled porcine insulin as tracer and human monocomponent insulin as standard (Novo Research Institute, Bagsvaerd, Denmark)[22]. Precipitation of the antigen-antibody complex was performed using an ethanol separation technique. The sensitivity of the assay was $0.005 \mathrm{nmol} / \mathrm{l}$, and the interassay coefficient of variation was $11 \%$. C-peptide concentrations were determined in duplicate with an RIA method [23]. The sensitivity of the C-peptide assay was 0.01 $\mathrm{nmol} / \mathrm{l}$ and the interassay coefficient of variation was $9 \%$. Lipoprotein fractions were separated according to Havel et al. [24] by sequential ultracentrifugation from blood samples taken after an overnight $(12 \mathrm{~h})$ fast, using a Ti 50 rotor in Sorvall OTD 65 preparative ultracentrifuge (Du Pont Instruments, Wilmington, Del., USA) [25]. The concentrations of cholesterol and triglycerides in total plasma and in the separate lipoprotein fractions were determined by enzymatic methods using commercial kits (kit no. 187313 for cholesterol and kit no. 297771 for triglyceride, Boehringer Mannheim). Serum nonesterified fatty acids (NEFA) were measured with a microfluorometric method [26]. Creatinine in serum and urine was analysed with a kinetic method (Kone Oy Reag, Espoo, Finland). Urinary albumin excretion rate (AER) was measured with radioimmunoassay (RIA) from three 24-h urine collections at baseline, and with immunoturbidimetry from three overnight urine collections at follow-up. The detection limit for the RIA method was $2 \mathrm{mg} / \mathrm{l}$, and the interassay coefficient of variation $5 \%$. The corresponding values for the immunoturbidimetric method were $5 \mathrm{mg} / \mathrm{l}$ and $7.5 \pm 1 \%$, respectively. Organ-specific antibodies (thyroid microsomal antibodies, thyroglobulin antibodies, islet-cell antibodies, and gastric parietal antibodies) were determined as previously described [13]. GAD antibodies were measured by a radioimmunoprecipitation assay [27]. The limit for positivity was set to $18 \mathrm{U}$, which exceeded the mean +3 SD for controls [9]. HLA typing was performed by a standard two-stage cytotoxicity method with a
Table 1. Causes of death during a 9-year follow-up in 38 type II diabetic patients

\begin{tabular}{ll}
\hline & $n$ \\
\hline Cardiovascular disease & 26 \\
- Myocardial infarction & 19 \\
- Heart failure & 2 \\
- Stroke & 5 \\
Uraemia & 1 \\
Infections & 1 \\
Neoplasms & 3 \\
Other causes $^{\text {a }}$ & 5 \\
Unknown $_{\text {Total }}$ & 2 \\
\hline
\end{tabular}

a Other causes of death included: liver cirrhosis, drowning, suicide, intestinal occlusion, and lung embolism

total of 120 antisera defining 11 A-locus, 20 B-locus, and 7 Cw-locus specificities. Eight DR specificities, DR1-DRw8, were determined with a minimum of 60 antisera.

Statistical analysis. All data are expressed as mean \pm SEM unless otherwise stated. Differences between group means were tested with analysis of variance (ANOVA), or covariance (ANCOVA) with age as a covariate, or Mann-Whitney test where appropriate, while Pearson's chi-square test or a twotailed Fisher's test was used to test frequency differences. AER, creatinine clearance, and total triglyceride concentration were analysed after $\log _{\mathrm{e}}$ transformation due to positively skewed distributions. Independent risk factors for mortality and macroangiopathy were identified with backward stepwise multiple logistic regression analysis. All data were analysed using a BMDP statistical package (Biomedical Data Processing version 7.0, 1992, Los Angeles, Calif., USA) except the logistic regression analyses which were performed with NCSS statistical software (Biomedical Data Processing, version 6.0.21, 1996). A $p$-value less than 0.05 was considered statistically significant, except in the univariate comparisons of continuous variables where a $p$-value less than 0.02 was required.

\section{Results}

\section{Baseline characteristics of deceased and surviving patients}

Thirty-eight patients $(29 \%)$ died during the followup. The majority $(68 \%)$ of the deaths were due to cardiovascular disease (Table 1). Mortality was associated with higher $\mathrm{HbA}_{1}$, and higher NEFA concentrations, lower HDL-cholesterol concentration, higher AER, and lower creatinine clearance at baseline (Table 2). In consequence, microalbuminuria was more prevalent in the deceased than in the living patients (45 vs $6 \%$ ). In addition, patients who died had a higher prevalence of macroangiopathy (61 vs $22 \%$ ) at baseline than patients who survived (Table 3). The difference in prevalence of cardiovascular disease at baseline was due to both cardiovascular and peripheral vascular disease. Of the patients con- 
Table 2. Baseline clinical characteristics of Type II diabetic patients who died or survived during the 9-year follow-up period

\begin{tabular}{|c|c|c|c|}
\hline & Deceased & Survived & $p$-value \\
\hline$n$ (male/female) & $38(21 / 17)$ & $93(46 / 47)$ & \\
\hline Age (years) & $59.5 \pm 0.8$ & $57.1 \pm 0.6$ & \\
\hline Duration of diabetes (years) & $10.4 \pm 0.8$ & $8.8 \pm 0.5$ & \\
\hline Insulin treatment $(\%)$ & 21 & 22 & \\
\hline Body mass index $\left(\mathrm{kg} / \mathrm{m}^{2}\right)$ & $27.1 \pm 0.6$ & $27.2 \pm 0.4$ & \\
\hline Systolic BP $(\mathrm{mmHg})$ & $154 \pm 4$ & $154 \pm 2$ & \\
\hline Diastolic BP (mmHg) & $85 \pm 3$ & $88 \pm 1$ & \\
\hline Fasting plasma glucose $(\mathrm{mmol} / \mathrm{l})$ & $11.7 \pm 0.6$ & $10.6 \pm 0.4$ & \\
\hline $\mathrm{HbA}_{1}(\%)$ & $10.8 \pm 0.3$ & $9.7 \pm 0.2$ & 0.002 \\
\hline Triglycerides $(\mathrm{mmol} / \mathrm{l})$ & $2.55 \pm 0.29$ & $2.26 \pm 0.24$ & \\
\hline VLDL-triglycerides $(\mathrm{mmol} / \mathrm{l})$ & $1.64 \pm 0.26$ & $1.34 \pm 0.17$ & \\
\hline LDL-triglycerides (mmol/l) & $0.60 \pm 0.04$ & $0.53 \pm 0.04$ & 0.007 \\
\hline Cholesterol $(\mathrm{mmol} / \mathrm{l})$ & $6.22 \pm 0.28$ & $6.32 \pm 0.14$ & \\
\hline HDL-cholesterol (mmol/l) & $1.24 \pm 0.05$ & $1.41 \pm 0.04$ & 0.007 \\
\hline $\mathrm{HDL}_{2}$-cholesterol $(\mathrm{mmol} / \mathrm{l})$ & $0.64 \pm 0.06$ & $0.77 \pm 0.04$ & 0.013 \\
\hline $\mathrm{HDL}_{3}$-cholesterol $(\mathrm{mmol} / \mathrm{l})$ & $0.59 \pm 0.02$ & $0.64 \pm 0.01$ & \\
\hline LDL-cholesterol (mmol/l) & $4.40 \pm 0.18$ & $4.24 \pm 0.11$ & \\
\hline VLDL-cholesterol (mmol/l) & $0.74 \pm 0.12$ & $0.63 \pm 0.09$ & \\
\hline NEFA (nmol/l) & $991 \pm 51$ & $857 \pm 35$ & 0.014 \\
\hline Fasting serum-C-peptide (nmol/l) & $0.55 \pm 0.05$ & $0.44 \pm 0.04$ & \\
\hline Fasting serum-insulin $(\mathrm{nmol} / \mathrm{l})$ & $0.16 \pm 0.01$ & $0.14 \pm 0.01$ & \\
\hline HOMA insulin resistance & $14.1 \pm 1.8$ & $10.8 \pm 0.8$ & \\
\hline Serum-creatinine $(\mu \mathrm{mol} / \mathrm{l})$ & $95 \pm 9$ & $79 \pm 2$ & \\
\hline Creatinine clearance $\left(\mathrm{ml} \cdot \mathrm{min}^{-1} \cdot 1.73 \mathrm{~m}^{-2}\right)$ & $89 \pm 4$ & $108 \pm 4$ & 0.003 \\
\hline $\operatorname{UAER}(\mathrm{mg} / 24 \mathrm{~h})$ & $3.0(1.0-78.0)$ & $16.0(1.0-300.0)$ & $<0.0001$ \\
\hline Current smoking (\%) & 37 & 19 & \\
\hline
\end{tabular}

All data are mean \pm SEM except UAER median (range) with $p$-values adjusted for age

Table 3. Baseline characteristics of micro- and macrovascular disease in Type II diabetic patients who died or survived during the 9 -year follow-up period

\begin{tabular}{|c|c|c|c|}
\hline & Deceased $(n=38)$ & Survived $(n=93)$ & $p$-value \\
\hline Microalbuminuria (\%) & 45 & 6 & $<0.0001$ \\
\hline Retinopathy (\%) & 42 & 16 & 0.002 \\
\hline Clinical neuropathy (\%) & 70 & 46 & 0.013 \\
\hline Neurophysiological neuropathy (\%) & 57 & 23 & $<0.001$ \\
\hline Valsalva ratio & $1.42 \pm 0.06$ & $1.52 \pm 0.03$ & 0.002 \\
\hline Tilt ratio & $1.25 \pm 0.06$ & $1.23 \pm 0.01$ & \\
\hline SD of heart rate at rest & $41.3 \pm 8.1$ & $32.8 \pm 1.7$ & \\
\hline$\Delta$ Heart rate at deep breathing & $20.4 \pm 2.6$ & $19.4 \pm 1.1$ & \\
\hline Macroangiopathy (\%) & 61 & 22 & $<0.0001$ \\
\hline Coronary heart disease (\%) & 50 & 13 & $<0.0001$ \\
\hline History of myocardial infarction (\%) & 18 & 6 & 0.038 \\
\hline History of stroke (\%) & 5 & 4 & \\
\hline ECG hard criteria (\%) & 24 & 5 & 0.002 \\
\hline Peripheral vascular disease (\%) & 27 & 9 & 0.006 \\
\hline Hypertension (\%) & 53 & 47 & \\
\hline Heart volume $\left(\mathrm{cc} / \mathrm{m}^{2}\right)$ & $425 \pm 17$ & $397 \pm 7$ & \\
\hline
\end{tabular}

All data are percentages or means \pm SEM with $p$-values adjusted for age. $\mathrm{SD}=$ standard deviation of the mean, $\Delta$ heart rate $=$ difference between maximum and minimum pulse frequency

sidered to have CHD, only $46 \%$ fulfilled the Minnesota hard criteria for ECGs (Minnesota codes 1.1-1.2), while $42 \%$ had a verified history of myocardial infarction. In addition, retinopathy (42 vs $16 \%$ ), clinical (70 vs $46 \%$ ) and neurophysiologically defined neuropathy (57 vs $23 \%$ ) were significantly more common among the deceased than the surviving patients. Likewise, autonomic neuropathy as indicated by a lower Valsalva ratio was more common in patients who died than in those who survived.
The HLA-DR4 genotype was more common in those who survived than in those who died (39 vs $21 \%$ ). Otherwise, there were no significant differences in the frequencies of HLA-types between the two groups. There was an increased prevalence of parietal cell antibodies in the surviving vs deceased patients (14 vs $5 \%$ ), otherwise the prevalence of organ-specific antibodies did not differ between the two groups (Table 4). In a subset of patients $(n=64)$ we also measured GAD antibodies. Only one of the patients 
Table 4. Frequency (\%) of HLA-DR and immunological markers in Type II diabetic patients who died or survived during the 9-year follow-up period

\begin{tabular}{llll}
\hline & $\begin{array}{l}\text { Deceased } \\
(n=38)\end{array}$ & $\begin{array}{l}\text { Survived } \\
(n=93)\end{array}$ & $p$-value \\
\hline HLA-DR1 & 37 & 32 & \\
HLA-DR2 & 18 & 28 & \\
HLA-DR3 & 32 & 36 & 0.048 \\
HLA-DR4 & 21 & 39 & \\
HLA-DR3/DR4 & 47 & 63 & \\
HLA-DR5 & 16 & 17 & \\
HLA-DR6 & 10 & 14 & \\
HLA-DR7 & 16 & 16 & \\
HLA-DR8 & 13 & 5 & \\
Thyroglobulin antibodies & 8 & 10 & \\
Microsomal antibodies & 27 & 19 & \\
Islet cell antibodies & 8 & 9 & \\
Parietal cell antibodies & 5 & 14 & \\
GAD antibodies & 7 (1 of & 18 (9 of & \\
& 14 patients $)$ & 50 patients $)$ & \\
& & & \\
\end{tabular}

who died $(7 \%)$ and nine patients who survived $(18 \%)$ were GAD positive $(p=\mathrm{NS})$. None of the 16 patients with macroangiopathy at baseline was GAD positive compared with $21 \%$ (10 out of 48 ) of the patients without signs of macroangiopathy $(p=0.054)$.

\section{Risk factors for mortality in multivariate analysis}

Independent risk factors for death were studied with backward stepwise multiple logistic regression analysis. The model included the variables which differed at baseline between deceased and surviving patients (age, $\mathrm{HbA}_{1}$, C-peptide, HDL-cholesterol, triglycerides, NEFA, creatinine clearance, AER, macroangiopathy, PVD, retinopathy, neurophysiological neuropathy, Valsalva ratio, HLA-DR4) together with gender. Of these, baseline AER, macroangiopathy, neuropathy, and glycaemic control were independently associated with death. (Table 5). Since lipids are known risk factors for macroangiopathy, we also tested whether lipids could be independent risk factors for mortality if macroangiopathy was removed from the model. In this analysis, AER, C-peptide, glycaemic control, and neuropathy were independent risk factors for death (Table 5). If microangiopathy was removed from the model glycaemic control and HDLcholesterol were independent risk factors for death (Table 5). Finally, we tested whether microvascular disease (AER, retinopathy, and neuropathy) was independently associated with death in the absence of macroangiopathy and lipids. In all these models AER and neuropathy remained independent risk factors for death, while retinopathy was associated with death only in the absence of other microvascular complications in the model or if glycaemic control was removed from the model (Table 5).

Variables associated with microangiopathy and macroangiopathy at baseline. Since both microangiopathy (baseline AER and neuropathy) and macroangiopathy contributed to the mortality of the Type II diabetic patients, we examined which factors were independently associated with microangiopathy (retinopathy, neuropathy, and microalbuminuria) and macroangiopathy using multiple logistic regression analysis.

Table 5. Multiple logistic regression analysis with any mortality as dependent variable. Complete data were available from 113 patients

\begin{tabular}{|c|c|c|c|}
\hline Variable & Coefficient & SEM & $p$-value \\
\hline \multicolumn{4}{|c|}{$\begin{array}{l}\text { Model includes: Gender, age, } \mathrm{HbA}_{1}, \ln (\text { fasting } \mathrm{C} \text {-peptide), HDL-cholesterol, } \ln (\text { triglycerides }), \mathrm{NEFA}, \ln (\mathrm{creatinine} \text { clearance }), \ln (\mathrm{AER}) \text {, } \\
\text { macroangiopathy at baseline, peripheral vascular disease, retinopathy, neurophysiological neuropathy, Valsalva ratio, and HLA-DR4. }\end{array}$} \\
\hline $\ln (\mathrm{AER})$ & 0.467 & 0.194 & 0.016 \\
\hline Macroangiopathy & 1.690 & 0.584 & 0.004 \\
\hline Neurophysiological neuropathy & 1.662 & 0.618 & 0.007 \\
\hline $\mathrm{HbA}_{1}$ & 0.362 & 0.153 & 0.018 \\
\hline $\ln ($ creatinine clearance) & -1.510 & 0.830 & 0.069 \\
\hline Fasting C-peptide & 2.044 & 1.108 & 0.065 \\
\hline \multicolumn{4}{|c|}{$\begin{array}{l}\text { Model includes: Gender, age, } \mathrm{HbA}_{1}, \ln (\text { fasting C-peptide), HDL-cholesterol, } \ln (\text { triglycerides }), \ln (\mathrm{AER}) \text {, neurophysiological neuropathy, } \\
\text { and retinopathy. }\end{array}$} \\
\hline $\ln (\mathrm{AER})$ & 0.497 & 0.175 & 0.005 \\
\hline Fasting C-peptide & 2.222 & 0.938 & 0.018 \\
\hline $\mathrm{HbA}_{1}$ & 0.304 & 0.143 & 0.034 \\
\hline Neurophysiological neuropathy & 1.179 & 0.522 & 0.024 \\
\hline \multicolumn{4}{|c|}{ Model includes: Gender, age, $\mathrm{HbA}_{1}, \ln$ (triglycerides), and HDL-cholesterol. } \\
\hline $\mathrm{HbA}_{1}$ & 0.313 & 0.110 & 0.005 \\
\hline HDL-cholesterol & -1.751 & 0.738 & 0.018 \\
\hline Age & 0.313 & 0.110 & 0.056 \\
\hline \multicolumn{4}{|c|}{ Model includes: Gender, age, $\ln ($ AER $)$, retinopathy, and neurophysiological neuropathy. } \\
\hline $\ln (\mathrm{AER})$ & 0.581 & 0.173 & 0.001 \\
\hline Neurophysiological neuropathy & 1.489 & 0.537 & 0.006 \\
\hline Retinopathy & 0.169 & 0.545 & 0.032 \\
\hline
\end{tabular}


Table 6. Clinical characteristics of Type II diabetic patients with no macroangiopathy at baseline who progressed or did not progress to macrovascular disease during the follow-up period

\begin{tabular}{|c|c|c|c|}
\hline & Progressor & Non-progressor & $p$-value \\
\hline$n$ (male/female) & $24(15 / 9)$ & $59(29 / 30)$ & \\
\hline Age (years) & $58.9 \pm 1.2$ & $55.7 \pm 0.8$ & 0.020 \\
\hline Duration of diabetes (years) & $9.5 \pm 0.9$ & $8.2 \pm 0.6$ & \\
\hline Insulin treatment $(\%)$ & 29 & 22 & \\
\hline Body mass index $\left(\mathrm{kg} / \mathrm{m}^{2}\right)$ & $27.4 \pm 0.8$ & $27.4 \pm 0.5$ & \\
\hline Systolic BP (mmHg) & $149 \pm 4$ & $154 \pm 3$ & \\
\hline Diastolic BP (mmHg) & $88 \pm 2$ & $88 \pm 1$ & \\
\hline Fasting plasma glucose $(\mathrm{mmol} / \mathrm{l})$ & $10.4 \pm 0.9$ & $10.5 \pm 0.4$ & \\
\hline $\mathrm{HbA}_{1}(\%)$ & $10.1 \pm 0.4$ & $9.7 \pm 0.2$ & \\
\hline Triglycerides (mmol/l) & $2.55 \pm 0.52$ & $2.17 \pm 0.30$ & \\
\hline VLDL-triglycerides (mmol/l) & $1.51 \pm 0.39$ & $1.28 \pm 0.21$ & \\
\hline LDL-triglycerides $(\mathrm{mmol} / \mathrm{l})$ & $0.54 \pm 0.04$ & $0.54 \pm 0.06$ & \\
\hline Cholesterol $(\mathrm{mmol} / \mathrm{l})$ & $6.95 \pm 0.32$ & $6.10 \pm 0.18$ & \\
\hline HDL-cholesterol (mmol/l) & $1.34 \pm 0.07$ & $1.46 \pm 0.05$ & \\
\hline $\mathrm{HDL}_{2}$-cholesterol (mmol/1) & $0.72 \pm 0.07$ & $0.82 \pm 0.05$ & \\
\hline $\mathrm{HDL}_{3}$-cholesterol $(\mathrm{mmol} / \mathrm{l})$ & $0.62 \pm 0.02$ & $0.63 \pm 0.02$ & \\
\hline LDL-cholesterol (mmol/l) & $4.80 \pm 0.28$ & $3.99 \pm 0.12$ & 0.012 \\
\hline VLDL-cholesterol (mmol/l) & $0.74 \pm 0.19$ & $0.62 \pm 0.11$ & \\
\hline NEFA (nmol/l) & $813 \pm 61$ & $881 \pm 50$ & \\
\hline Fasting serum C-peptide (nmol/l) & $0.38 \pm 0.05$ & $0.47 \pm 0.05$ & \\
\hline Fasting serum insulin $(\mathrm{nmol} / \mathrm{l})$ & $0.14 \pm 0.02$ & $0.14 \pm 0.02$ & \\
\hline HOMA insulin resistance & $11.6 \pm 2.6$ & $10.6 \pm 1.0$ & \\
\hline Serum creatinine $(\mu \mathrm{mol} / \mathrm{l})$ & $96 \pm 13$ & $78 \pm 2$ & \\
\hline Creatinine clearance $\left(\mathrm{ml} \cdot \mathrm{min}^{-1} \cdot 1.73 \mathrm{~m}^{-2}\right)$ & $108 \pm 7$ & $106 \pm 5$ & \\
\hline $\operatorname{UAER}(\mathrm{mg} / 24 \mathrm{~h})$ & $5.0(1.0-125.0)$ & $2.0(1.0-79.0)$ & \\
\hline AER progression (\%) & 57 & 25 & 0.009 \\
\hline Current smoking (\%) & 38 & 17 & $(0.043)$ \\
\hline Microalbuminuria (\%) & 13 & 8 & \\
\hline Retinopathy (\%) & 25 & 21 & \\
\hline Clinical neuropathy (\%) & 63 & 40 & \\
\hline Neurophysiological neuropathy (\%) & 32 & 30 & \\
\hline Valsalva ratio & $1.50 \pm 0.06$ & $1.55 \pm 0.04$ & \\
\hline Tilt ratio & $1.20 \pm 0.02$ & $1.23 \pm 0.02$ & \\
\hline SD of heart rate at rest & $34.6 \pm 3.8$ & $30.4 \pm 1.9$ & \\
\hline$\Delta$ Heart rate at deep breathing & $20.4 \pm 2.4$ & $18.1 \pm 1.2$ & \\
\hline Hypertension (\%) & 38 & 49 & \\
\hline Heart volume $\left(\mathrm{cc} / \mathrm{m}^{2}\right)$ & $384 \pm 15$ & $412 \pm 8$ & \\
\hline
\end{tabular}

All continuous data are mean \pm SEM except UAER median (range) with $p$-values adjusted for age

The model included age, gender, $\mathrm{HbA}_{1}$, C-peptide, HDL-cholesterol, triglycerides, NEFA, creatinine clearance, and HLA-DR4. Retinopathy was independently associated with $\mathrm{HbA}_{1}(p=0.0001)$ and age $(p=0.005)$, neurophysiologically assessed neuropathy was associated with male sex $(p=0.0001)$ and $\mathrm{HbA}_{1}(p=0.0009)$, while the presence of microalbuminuria was associated with $\operatorname{HbA}_{1}(p=0.036)$ and creatinine clearance $(p=0.036)$. Macroangiopathy was associated with older age $(p=0.002)$ and low HDL-cholesterol $(p=0.004)$ concentrations.

Risk factors for cardiovascular events in patients free of cardiovascular disease at baseline. It is possible that risk factors for cardiovascular morbidity and mortality differ depending upon whether cardiovascular disease develops early or late in the course of diabetes. In an analysis of a subgroup of patients free from cardiovascular disease at baseline, cardiovascular morbidity and mortality were associated with older age, higher LDL-cholesterol concentra-
Table 7. Multiple logistic regression analysis with cardiovascular events in Type II diabetic patients with no macroangiopathy at baseline as dependent variable. Complete data were available from 79 patients

\begin{tabular}{lcll}
\hline Variable & Coefficient & SEM & $p$-value \\
\hline LDL-cholesterol & 0.969 & 0.322 & 0.003 \\
Age & 0.181 & 0.065 & 0.005 \\
HbA $_{1}$ & 0.353 & 0.173 & 0.041 \\
HDL-cholesterol & -1.661 & 0.972 & 0.087
\end{tabular}

Model includes: Age, $\mathrm{HbA}_{1}, \ln ($ fasting C-peptide), $\ln$ (triglycerides), LDL-cholesterol, HDL-cholesterol, NEFA, $\ln ($ AER $), \ln ($ creatinine clearance), retinopathy, neurophysiological neuropathy, Valsalva ratio, HLA-DR4, parietal cell antibodies, and history of smoking

tions, and smoking. In contrast to the findings in the total cohort, no difference was observed in glycaemic control or blood pressure between patients who developed or did not develop cardiovascular events. Although baseline AER did not differ between the two 
groups, progression of AER from normoalbuminuria to microalbuminuria or macroalbuminuria was significantly more common in patients who developed compared to those who did not develop cardiovascular disease during the follow-up period. (Table 6). These factors together with the risk factors operative in the total study $\left(\mathrm{HbA}_{1}\right.$, triglycerides, HDL-cholesterol, NEFA, C-peptide, creatinine clearance, AER, retinopathy, neuropathy, and Valsalva ratio) were then entered into a multiple logistic regression analysis. In this analysis, LDL-cholesterol, age, and $\mathrm{HbA}_{1}$ were risk factors for cardiovascular morbidity and mortality (Table 7).

\section{Discussion}

This prospective study showed a total mortality of $29 \%$ during the 9-year follow-up period, cardiovascular events being the main cause of death. In a multiple logistic regression analysis mortality was associated with baseline glycaemic control, AER, neuropathy and macroangiopathy. However, the association between risk factors and outcome is not that simple. In the present study as well as in previous studies, Type II diabetes was considered as a homogenous disease entity. This is most likely not the case; Type II diabetes is rather a heterogeneous disorder which can be subdivided into subgroups based upon genetic and immunological markers [8]. Therefore, one has to consider the possibility that disease heterogeneity influences the development of complications.

Somewhat surprisingly, Type I diabetes susceptibility HLA genes, particularly HLA-DR4, were recently proposed to explain the majority of Type II diabetes in Finland [28]. The current finding of increased frequency of DR4 in patients who survived compared with deceased patients ( 39 vs $21 \%$ ), may provide an explanation for these unexpected findings. Tuomilehto-Wolf et al. [28] reported a prevalence of HLA-DR 4 of $57 \%$ in elderly Finnish men with Type II diabetes. The patients had an average age of 77 years, which is far beyond the life expectancy for a Finnish man with Type II diabetes. It is therefore likely, that the elderly men in the study by Tuomilehto-Wolf et al. represented a surviving Type II diabetic subgroup free of macrovascular disease [28]. The corollary of this finding is that the presence of Type I susceptibility genes in Type II diabetic patients seems to protect from macrovascular disease. In support of this, GAD antibody positive patients had a tendency to lower frequency of cardiovascular complications. The findings of increased prevalence of parietal cell antibodies in surviving Type II diabetic patients could also be related to an increase in either HLA-DR3 or HLA-DR4, which are known to be associated with autoimmune disease [29].
Although patients who survived had a higher prevalence of HLA-DR4 and parietal cell antibodies (and a tendency to higher prevalence of GAD antibodies) than patients who died, neither HLA-DR4 nor the presence of autoimmunity were associated with the outcome in the multivariate analysis. This could suggest that the (protective) effect of HLA is mediated through other mechanisms included in the analysis. HLA-DR4 and autoimmune markers are particularly increased in Type II diabetic patients with some degree of beta-cell dysfunction [13]. In contrast, high C-peptide concentrations most likely reflecting insulin resistance were also associated with mortality in the model without macroangiopathy (Table 5). Taken together with the reported long survival in Type II diabetic men with increased prevalence of HLA-DR4, the data suggest that HLA-DR4 identifies a subgroup of Type II diabetes characterised by low C-peptide, relatively normal insulin sensitivity, and reduced risk of cardiovascular disease.

The lipid profile in the patients who died was compatible with the lipid profile characteristic of the metabolic syndrome, i.e. increase in total triglyceride (both VLDL and LDL subfractions) and decrease in HDL-cholesterol (both $\mathrm{HDL}_{2}$ and $\mathrm{HDL}_{3}$ subfractions). Although not measured at baseline, increased amounts of atherogenic small dense LDL-cholesterol particles are known to be associated with these lipid abnormalities [30]. It can therefore be anticipated that the increase in the VLDL-particles partially reflected the presence of small dense LDL [31]. The patients who died during follow-up thereby fulfilled four of the criteria for the metabolic syndrome, i.e. high triglycerides, low HDL-cholesterol, insulin resistance (higher C-peptide) and microalbuminuria, whereas we could not find any evidence for higher blood pressure or obesity. Regarding obesity we have to make a reservation for abdominal obesity which was not assessed in the study. The presence of the metabolic syndrome is further supported by the elevated NEFA concentrations, since the metabolic syndrome has been associated with abnormalities in visceral fat lipolysis and elevated NEFA concentrations [32]. NEFA is a substrate for the production of atherogenic VLDL-triglycerides in the liver; in addition, elevated circulating NEFA levels could also lead to increased NEFA uptake and re-esterification in muscle. In support of this, insulin-resistant subjects have increased triglyceride concentrations in muscle [33, 34], and there is accumulating evidence for the existence of intracellular lipolysis [35] and fat oxidation in muscle [36]. An increased fat oxidation could then by substrate competition (Randle cycle) lead to decreased insulin-stimulated glucose metabolism [37].

The present study confirmed earlier prospective data on the predictive value of microalbuminuria for both total, and cardiovascular mortality in Caucasian populations [4,38-42]. Both all-cause (74 vs 19\%) 
and cardiovascular mortality (57 vs $21 \%$ ) were higher in microalbuminuric compared to normoalbuminuric Type II diabetic patients. In addition, AER predicted mortality in a multiple logistic regression analysis. Although microalbuminuria predicts diabetic nephropathy and thereby end-stage renal disease in Type II diabetic patients [43], increased mortality in end-stage renal disease cannot explain the increased total mortality in patients with microalbuminuria, since most Scandinavian Type II diabetic patients die before they develop overt renal disease [4,42]. In support of this, only 5 of the 86 surviving, restudied patients $(6 \%)$ developed diabetic nephropathy, and only 1 patient died of end-stage renal disease. Microalbuminuria in these patients may reflect generalised vascular dysfunction rather than actual renal disease [44]. Accordingly, Stehouwer et al. [45] have shown that microalbuminuria in Type II diabetes is associated with new cardiovascular events only in the presence of increased von Willebrand factor, a marker of endothelial dysfunction. Insulin resistance could also link microalbuminuria to macrovascular disease. We have earlier shown that microalbuminuria is associated with insulin resistance in both Type II diabetic patients and their non-diabetic relatives [46, 47]. Since insulin resistance is a risk factor for cardiovascular disease, it could be the common denominator for microalbuminuria and other cardiovascular risk factors characteristic of the insulin resistance syndrome [7].

In the present study, macroangiopathy and microangiopathy (neuropathy and AER) were independent risk factors for total mortality. In contrast, several known cardiovascular risk factors (triglycerides, HDL-cholesterol, blood pressure) did not predict mortality. If these variables were strongly associated with microangiopathy and/or macroangiopathy per se, this could remove them from the multiple logistic regression analysis. To test this hypothesis, we performed multiple logistic regression analyses using baseline microangiopathy (retinopathy, neuropathy, and microalbuminuria) and macroangiopathy as dependent variables. Microangiopathy, but not macroangiopathy, was associated with poor glycaemic control $\left(\mathrm{HbA}_{1}\right)$. However, glycaemic control was weakly associated with later cardiovascular events in patients free from such disease at baseline. Previous prospective studies have provided discrepant results regarding a role for glycaemic control in promoting macrovascular disease $[3,4,38-40,48]$. In this prospective study, worse glycaemic control at baseline was associated with an increased mortality. Part of this effect of hyperglycaemia on mortality could be mediated through increased mortality associated with microvascular disease, especially nephropathy. Another possibility is that insulin-resistant patients had higher $\mathrm{HbA}_{1}$ concentrations and that insulin resistance mediated the increased risk for cardiovascular disease.
Interestingly, in the present study, neuropathy, as assessed by neurophysiological methods, was an independent risk factor for all-cause mortality, which was not reflected by the clinical staging. It is obvious that the clinical diagnostic methods were too insensitive for this purpose, which could partly explain why neuropathy rarely is considered an independent risk factor for mortality. The autonomic nervous function was assessed using four different methods in order to increase the specificity of the diagnosis. However, only a lower Valsalva ratio was predictive of mortality in a univariate $(p=0.002)$, but not in a multivariate analysis. To some extent, these data differ from those in a recent 10-year follow-up study of newly diagnosed Finnish Type II diabetic patients in which autonomic neuropathy was a strong predictor of cardiovascular mortality, even after adjustment for CHD, cardiovascular risk factors, and glycaemic control [49]. It is possible that the effect of autonomic neuropathy on mortality was attenuated by the effect of poor glycaemic control, a factor which was strongly associated with autonomic neuropathy in this study.

When we separately analysed patients without macroangiopathy at baseline conventional risk factors such as LDL-cholesterol and age were associated with the development of macrovascular disease. In this subgroup of patients baseline AER was not a risk factor for macroangiopathy. A potential explanation for this discrepancy is that those with macrovascular disease at baseline represented a high-risk group, the majority of whom had died during the follow-up. In these patients, the metabolic syndrome seems to be the strongest predictor of death. However, conventional risk factors such as high LDL-cholesterol concentrations are also operative, but this effect is not unmasked until the high-risk group has been omitted from the analysis.

In conclusion, mortality in Type II diabetic patients is primarily caused by macrovascular disease. In addition to pre-existing signs of macrovascular disease, poor glycaemic control, microalbuminuria, and neuropathy were independent risk factors for cardiovascular mortality. If patients had no macroangiopathy at baseline, conventional cardiovascular risk factors, such as LDL-cholesterol, were associated with cardiovascular morbidity also in Type II diabetes. Therefore, most risk factors are modifiable by intensified treatment, particularly of hyperglycaemia and dyslipidaemia.

Acknowledgements. We wish to express our gratitude to the late Professor Esko Nikkilä for his valuable advice with planning of the study and to Ms. Seija Heikkinen, Ms. Marjo Rissanen, Mr. Esa Laurila, Ms. Marita von Bell, Ms. Päivikki Määttälä, and Ms. Outi Nikulainen for skilled technical assistance, and Tiinamaija Tuomi M.D. for analysing GAD antibodies. This study was supported by grants from the Finnish Medical Society (Finska Läkaresällskapet), the Finnish Foundation for 
Diabetes Research of the Finnish Diabetes Association, the Foundation for Life and Health (Liv och Hälsa), The Sigrid Juselius Foundation and the Perklén Foundation.

\section{References}

1. Hanssen KF, Dahl-Jörgensen K, Lauritzen T, Feldt-Rasmussen B, Brinchmann-Hansen O, Deckert T (1986) Diabetic control and microvascular complications: the nearnormoglycaemic experience. Diabetologia 29: 677-684

2. Abraira C, Colwell J, Nuttall F et al. (1997) Cardiovascular events and correlates in the Veterans Affairs Diabetes Feasibility Trial. Veterans Affairs Cooperative Study on Glycemic Control and Complications in Type II Diabetes. Arch Intern Med 157: 181-188

3. Kuusisto J, Mykkänen L, Pyörälä K, Laakso M (1994) NIDDM and its metabolic control predict coronary heart disease in elderly subjects. Diabetes 43: 960-967

4. Gall M-A, Borch-Johnsen K, Hougaard P, Nielsen FS, Parving H-H (1995) Albuminuria and poor glycemic control predict mortality in NIDDM. Diabetes 44: 1303-1309

5. West KM, Ahuja MMS, Bennett PH et al. (1983) The role of circulating glucose and triglyceride concentrations and their interactions with other "risk factors" as determinants of arterial disease in nine diabetic population samples from the WHO Multinational Study. Diabetes Care 6: 361-369

6. Uusitupa MIJ, Niskanen LK, Siitonen O, Voutilainen E, Pyörälä K (1990) 5-year incidence of atherosclerotic vascular disease in relation to general risk factors, insulin level, and abnormalities in lipoprotein composition in non-insulin-dependent diabetic and nondiabetic subjects. Circulation 82: 27-36

7. Reaven GM (1988) Role of insulin resistance in human disease. Diabetes 37: 1595-1607

8. Groop L, Tuomi T (1997) Non-insulin dependent diabetes mellitus - A collision between thrifty genes and an affluent society. Ann Med 29: 37-53

9. Tuomi T, Groop LC, Zimmet PL, Rowley MJ, Knowles W, Mackay IR (1993) Antibodies to glutamic acid decarboxylase reveal latent autoimmune diabetes mellitus in adults with a non-insulin-dependent onset of disease. Diabetes 42: 359-362

10. Turner R, Stratton I, Horton Vet al. (1997) UKPDS 25: autoantibodies to islet-cell cytoplasm and glutamic acid decarboxylase for prediction of insulin requirement in type 2 diabetes. Lancet 350: 1288-1293

11. Lehto M, Tuomi T, Mahtani M et al. (1997) Characterization of the MODY3 phenotype: early-onset diabetes caused by an insulin secretion defect. J Clin Invest 99: 582-591

12. Isomaa B, Henricsson M, Lehto M et al. (1998) Chronic diabetic complications in patients with MODY3 diabetes. Diabetologia 41: 467-473

13. Groop L, Miettinen A, Groop P-H, Meri S, Koskimies S, Bottazzo GF (1988) Organ-specific autoimmunity and HLA-DR antigens as markers for $\beta$-cell destruction in patients with type II diabetes. Diabetes 37: 99-103

14. Agardh D, Gaur LK, Agardh E, Landin-Olsson M, Agardh C-D, Lernmark Å (1996) HLA-DQB1*0201/0302 is associated with severe retinopathy in patients with IDDM. Diabetologia 39: 1313-1317

15. World Health Organization Study Group on Diabetes Mellitus (1985) Technical report series No 727, WHO, Geneva

16. Faber OK, Binder C (1977) C-peptide response to glucagon. A test for the residual $\beta$-cell function in diabetes mellitus. Diabetes 26: 605-610
17. Matthews DR, Hosker JP, Rudenski AS, Naylor BA, Treacher DF, Turner RC (1985) Homeostasis model assessment: insulin resistance and $\beta$-cell function from fasting plasma glucose and insulin concentrations in man. Diabetologia 28: 412-419

18. Rose GA, Blackburn H (1968) Cardiovascular survey methods. World Health Organization, Geneva, pp 137-154

19. Darling RC, Raines JK, Brener BJ, Austen WG (1972) Quantitative segmental pulse volume recorder: a clinical tool. Surgery 72: 873-887

20. Lepäntalo M, Lindfors O, Pekkola P (1983) The ankle/arm systolic blood pressure ratio as a screening test for arterial insufficiency in the lower limb. Ann Chirurg Gynaecol 72: $57-62$

21. Nielsen PE, Bell G, Lassen NA (1972) The measurement of digital systolic blood pressure by strain gauge technique. Scand J Lab Invest 29: 371-379

22. Heding LG (1972) Determination of total serum insulin (IRI) in insulin-treated diabetic patients. Diabetologia 8: 260-266

23. Heding LG (1975) Radioimmunological determination of human C-peptide in serum. Diabetologia 11: 541-548

24. Havel RJ, Eder HA, Bragdon JH (1955) The distribution and chemical composition of ultracentrifugally separated lipoproteins in human serum. J Clin Invest 34: 1345-1353

25. Sane T, Nikkilä EA (1988) Very low density lipoprotein triglyceride metabolism in relatives of hypertriglyceridemic probands. Evidence for genetic control of triglyceride removal. Arteriosclerosis 8: 217-226

26. Miles J, Glasscock R, Aikens J, Gerich J, Haymond M (1983) A microfluorometric method for the determination of free fatty acids in plasma. J Lipid Res 24: 96-99

27. Rowley MJ, Mackay IR, Chen Q-Y, Knowles W, Zimmet PZ (1992) Antibodies to glutamic acid decarboxylase discriminate major types of diabetes mellitus. Diabetes 41: $548-551$

28. Tuomilehto-Wolf E, Tuomilehto J, Hitman GA et al. (1993) Genetic susceptibility to non-insulin dependent diabetes mellitus and glucose intolerance are located in HLA region. BMJ 307: 155-159

29. Charron D (1990) Molecular basis of human leukocyte antigen class II disease associations. Adv Immunol 48: 107-159

30. Austin MA, King MC, Vranizan KM, Krauss RM (1990) Atherogenic lipoprotein phenotype. A proposed genetic marker for coronary heart disease risk. Circulation 82: 495-506

31. Lahdenperä S, Syvänne M, Kahri J, Taskinen M-R (1996) Regulation of low-density lipoprotein particle size distribution in NIDDM and coronary heart disease: importance of serum triglycerides. Diabetologia 39: 453-461

32. Arner P (1995) Differences in lipolysis between human subcutaneous and omental adipose tissues. Ann Med 27: 435-438

33. Pan DA, Lillioja S, Kriketos AD et al. (1997) Skeletal muscle triglyceride levels are inversely related to insulin action. Diabetes 46: 983-988

34. Eriksson K-F, Laurila E, Kiens B, Groop L (1997) Skeletal muscle triglycerides in impaired glucose tolerance and NIDDM. Diabetologia 40 [Suppl 1]:A286 (Abstract)

35. Reynisdottir S, Ellerfeldt K, Wahrenberg H, Lithell H, Arner P (1994) Multiple lipolysis defects in the insulin resistance (metabolic) syndrome. J Clin Invest 93: 2590-2599

36. Groop LC, Bonadonna RC, Shank M, Petrides AS, DeFronzo RA (1991) Role of free fatty acids and insulin in determining free fatty acid and lipid oxidation in man. J Clin Invest 87: 83-89 
37. Saloranta C, Groop L (1996) Interactions between glucose and FFA metabolism in man. Diabetes/Metabol Rev 12: $15-36$

38. Mattock MB, Morrish NJ, Viberti GC, Keen H, Fitzgerald AP, Jackson G (1992) Prospective study of microalbuminuria as predictor of mortality in NIDDM. Diabetes 41: 736-741

39. Damsgaard EM, Fröland A, Jörgensen OD, Mogensen C-E (1992) Eight to nine year mortality in known non-insulin dependent diabetics and controls. Kidney Int 41: 731-735

40. Neil A, Hawkins M, Potok M, Thorogood M, Cohen D, Mann J (1993) A prospective population-based study of microalbuminuria as a predictor of mortality in NIDDM. Diabetes Care 16: 996-1003

41. MacLeod JM, Lutale J, Marshall SM (1995) Albumin excretion and vascular deaths in NIDDM. Diabetologia 38: 610-616

42. Niskanen L, Penttilä I, Parviainen M, Uusitupa MIJ (1996) Evolution, risk factors, and prognostic implications of albuminuria in NIDDM. Diabetes Care 19: 486-493

43. Mogensen CE (1984) Microalbuminuria predicts clinical proteinuria and early mortality in maturity-onset diabetes. N Engl J Med 310: 356-360

44. Deckert T, Feldt-Rasmussen B, Borch-Johnsen K, Jensen T, Kofoed-Enevoldsen A (1989) Albuminuria reflects widespread vascular damage. The Steno hypothesis. Diabetologia 32: 219-226

45. Stehouwer CDA, Nauta JJP, Zeldenrust GC, Hackeng WHL, Donker AJM, den Ottolander GJH (1992) Urinary albumin excretion, cardiovascular disease, and endothelial dysfunction in non-insulin dependent diabetes mellitus. Lancet 340: 319-323

46. Groop L, Ekstrand A, Forsblom C et al. (1993) Insulin resistance, hypertension and microalbuminuria in patients with type 2 (non-insulin-dependent) diabetes mellitus. Diabetologia 36: 642-647

47. Forsblom CM, Eriksson JG, Ekstrand AV, Teppo A-M, Taskinen M-R, Groop LC (1995) Insulin resistance and abnormal albumin excretion in non-diabetic first-degree relatives of patients with NIDDM. Diabetologia 38: 363-369

48. Uusitupa MIJ, Niskanen LK, Siitonen O, Voutilainen E, Pyörälä K (1993) Ten-year cardiovascular mortality in relation to risk factors and abnormalities in lipoprotein composition in type 2 (non-insulin-dependent) diabetic and nondiabetic subjects. Diabetologia 36: 1175-1184

49. Töyry JP, Niskanen LK, Mäntysaari MJ, Länsimies EA, Uusitupa MIJ (1996) Occurrence, predictors, and clinical significance of autonomic neuropathy in NIDDM. Tenyear follow-up from the diagnosis. Diabetes 45: 308-315 